\title{
Formação inicial e continuada de professores(as) de história: impactos na prática docente
}

\author{
Initial and continuing training of history teachers: impacts on \\ teaching practice
}

\section{Formación inicial y continua de profesores de historia: impactos en la práctica docente}

\author{
Maria Cristina Dantas Pina' \\ Universidade Estadual do Sudoeste da Bahia, Departamento de História e do Programa de \\ Pós-graduação em Educação, Professora titular. \\ https://orcid.org/0000-0003-1787-8541 \\ Edinalua Padre Aguiar ${ }^{2}$ \\ Universidade Estadual do Sudoeste da Bahia, Departamento de História e do Programa de \\ Pós-graduação em Educação, Professora adjunta. \\ http://orcid.org/0000-0001-6940-6496 \\ Iracema Oliveira Lima ${ }^{3}$ \\ Universidade Estadual do Sudoeste da Bahia, Departamento de História e do Programa de \\ Pós-graduação em Educação, Professora titular. \\ http://orcid.org/0000-0002-6761_3704
}

Resumo: 0 texto propõe uma discussão acerca da relação entre formação inicial e continuada e prática docente de professores de História que atuam na Educação Básica. A discussão será conduzida com base na pergunta: "Em que medida a formação, em diferentes niveis, reflete na prática docente dos professores?". A análise toma por base os resultados obtidos por meio da pesquisa Ensinar História: um estudo sobre as práticas de ensino e a produção de narrativas históricas por professores de História da Educação Básica (Paraná - São Paulo - Bahia - Goiás 1998-2014), coordenada pela professora Marlene Cainelli (UEL), tendo como fundamento as referências conceituais da Educação Histórica. Para este texto fizemos um recorte analisando as práticas dos professores da Bahia. Os dados foram analisados com base na análise de conteúdo e apresentados de forma contextualizada, portanto, dizem respeito ao universo investigado. Cruzando os dados do perfil dos professores com os referentes às escolhas metodológicas, não visualizamos diferenças marcantes que indiquem aprimoramento proporcionado por maior tempo e grau de formação; no tocante às narrativas sobre temas históricos, alguns professores

Doutora em Educação pela Universidade Estadual de Campinas; Mestre em História pela Universidade Federal da Bahia. 
com mestrado concluído ou em curso à época da pesquisa apresentam relatos mais organizados, atualizados e de maior nível de complexidade.

Palavras-chave: Formação docente. Prática de ensino. Educação Histórica.

Abstract: The text purposes a discussion between ongoing formation and practical instruction based on elementary school history teachers. The discussion will be conducted based on the question: "In what extent the formation, in different degrees, reflect on teacher's practice?". The analysis takes the results obtained through the research project Teaching history: a study about the teaching practice and historical narrative productions by elementary school history teachers (Paraná - São Paulo Bahia - Goiás 1998-2014), coordinated by teacher Marlene Cainelli (UEL), based on conceptual references of historical education. In this text, we have made a selection analyzing history teachers practices from Bahia. The data were analyzed based on the analysis content, and presented contextually, thus, it is mainly about the investigated universe. Crossing the teacher's profile data with the chosen methodologies, we did not notice any outstanding differences which indicate enhancement by part of the time or the formation degree. The teachers with Master's degree or working on college presented more organized, complex and updated narratives about historical themes.

Keywords: Teacher training. Teaching practice. Historical education.

Resumen: El texto propone una discusión sobre la relación entre la educación inicial y continua y la práctica docente de los profesores de historia que trabajan en Educación Básica. La discusión se realizará con base en la pregunta: "¿En qué medida la capacitación, en diferentes niveles, refleja la práctica docente de los profesores?". El análisis se basa en los resultados obtenidos a través de la investigación Historia de la enseñanza: un estudio sobre prácticas docentes". y la producción de narraciones históricas por docentes de Historia de la Educación Básica (Paraná - São Paulo - Bahia - Goiás 1998-2014), coordinada por la professora Marlene Cainelli (UEL), basada en las referencias conceptuales de Educación Histórico. Para este texto hicimos un corte analizando las prácticas de los maestros de Bahia. Los datos fueron analizados en base al análisis de contenido y presentados de manera contextualizada, por lo tanto, se relacionan con el universo investigado. Cruzando los datos del perfil de los docentes con los que se refieren a las opciones metodológicas, no vemos diferencias marcadas que indiquen una mejora proporcionada por un mayor tiempo y grado de educación; con respecto a las narrativas sobre temas históricos, algunos docentes con un título de maestría completado o en progreso en el momento de la investigación, presentan informes más organizados, actualizados y de mayor nivel de complejidad.

Palabras clave: Formación del profesorado. Práctica docente. Educación histórica.

Recebido em 6 de setembro de 2019 Aceito em 1 de março 2020 Publicado em 22 de julho de 2020 


\section{INTRODUÇÃO}

Este texto propõe uma discussão acerca da formação inicial e continuada e a prática docente de professores de História que atuam na Educação Básica. A discussão será conduzida com base na pergunta: "Em que medida a formação, em diferentes níveis, reflete na prática docente dos professores?". Nesse sentido, fizemos um recorte analisando as práticas dos professores da Bahia, intentando relacioná-las com a trajetória de formação que esses professores têm realizado ao longo da sua atuação profissional, interrogando se essas práticas se modificam/aperfeiçoam de acordo com o nível de formação.

A análise toma por base os dados obtidos por meio da pesquisa Ensinar História: um estudo sobre as práticas de ensino e a produção de narrativas históricas por professores de História da Educação Básica (Paraná - São Paulo - Bahia - Goiás 1998-2014), coordenada pela professora Marlene Cainelli (UEL), que envolveu pesquisadores de instituições diversas e nos referidos estados. A construção do questionário de pesquisa foi realizada em conjunto, com base nas referências conceituais da Educação Histórica, e foi organizado em três partes: 1. Identificação - informações sobre formação, atuação profissional, idade, situação de trabalho; 2. Narrativas - questões que desafiavam o professor a construir narrativas sobre acontecimentos históricos em situação de ensino-aprendizagem; 3. Metodologias questões sobre opções e usos de metodologias em sala de aula. Neste texto, nossa análise se concentra nos dados referentes aos professores da Bahia, totalizando 1 questionários.

Para responder à problemática por nós proposta, utilizamos o primeiro e o terceiro blocos do instrumento, recorrendo a alguns exemplos pontuais do segundo bloco. A intenção foi visualizar a formação e a trajetória, relacionando-as com as opções feitas na prática docente. Os dados foram analisados com base na técnica da análise de conteúdo e apresentados de forma contextualizada, portanto, dizem respeito ao universo investigado. Nossa pretensão não é tomar as conclusões de maneira universalizante, mas certamente indicam práticas recorrentes em outros espaços.

Assim, por meio das narrativas dos sujeitos dessa pesquisa sobre aspectos de sua prática, entende-se ser possível perceber como pensam a História e quais são suas escolhas metodológicas no cotidiano de sala de aula; como reinventam e reconstroem a história em situação de ensino.

0 texto está organizado em três partes, além desta introdução. Inicialmente apresentam-se os sujeitos, professores de História, destacando seu percurso formativo e 
escolhas profissionais, como também suas condições de trabalho. A intenção é visualizar a trajetória formativa desses professores e o que dela aparece nas suas práticas.

Em seguida, adentra-se nas práticas, por meio das respostas sobre escolhas metodológicas e estratégias adotadas em sala, analisam-se os sentidos atribuídos por esses sujeitos ao ensino de História, bem como a manutenção de práticas tradicionais e/ou inovações nas aulas de História. Como, quais recursos e quais práticas os professores de História têm adotado em suas aulas? Essa é a questão perseguida.

Por fim, relacionam-se as práticas com a formação, buscando perceber diferenças e/ou influências entre elas e de que maneira a formação e a trajetória docentes marcam suas práticas.

\section{ESCOLHAS FORMATIUAS E TRAJETÓRIA DOS PROFESSORES DE HISTÓRIA}

A identidade profissional, parte das identidades que compõem o sujeito, constituise num processo contínuo do refazer-se do indivíduo, rompe com o paradigma do qual esta se constituiria a partir de treinamento de habilidades, procedimentos e técnicas previamente estabelecidas e testadas. Ao analisar o processo formativo, procuramos deslindar como é pavimentado o percurso histórico da formação profissional do docente licenciado em História. Embora reconheçamos que essa construção aconteça gradualmente, procuramos, com base nos questionários, identificar como um grupo de 1 professores do Estado da Bahia vão se constituindo como professores de ensino de História, associada à perspectiva de compreender como a formação continuada impacta sobre o seu fazer em sala de aula, tanto nas etapas do planejamento quanto na execução e avaliação da sua proposta metodológica.

Refletindo acerca das escolhas formativas e trajetórias dos professores de História entrevistados, recorremos às informações expressas na primeira parte do questionário que abordam os seguintes aspectos: gênero, estado civil, idade, formação em nível superior, ano de formação, pós-graduação, tempo que exerce a profissão, vínculo empregatício, nível e modalidade de ensino em que atua, número de disciplinas que ministra, disciplinas que ministra, regime de trabalho, formação continuada e número de alunos.

Segundo Nóvoa (1992), Pimenta (1999) e Libâneo (2004), a formação profissional do sujeito necessita de tempo para se constituir e ocorre num processo que dialoga frequentemente com novas abordagens, possibilidades e inovações, ao mesmo tempo com outros sujeitos que coletivamente impactarão na constituição dessa identidade cambiante. 
Acompanhando o pensamento de Schmidt (1996, p. 117), espera-se que esse conjunto de condicionantes

\footnotetext{
[...] seja o promotor da união entre a competência acadêmica (domínio dos saberes) e a competência pedagógica (domínio da transmissão do saber), aliando competência, convicções e experiências de vida. A sua autoridade residiria, também, na capacidade de estabelecer uma espécie de comunicação individual com o seu aluno, levando-o à uma intimidade com um certo passado ou, quem sabe, até com um determinado presente.
}

Nesta pesquisa analisamos como foi sendo constituído o perfil de $\uparrow$ docentes que atuam na Rede Estadual de Educação Básica da Bahia. Identificamos que destes apenas um professor ainda está cursando a graduação, não pertencendo, portanto, ao quadro efetivo de professores do Estado da Bahia como os demais, sendo seu vínculo de trabalho temporário caracterizado como Regime Especial de Direito Administrativo (REDA). Destacase que a ausência de realização de concursos públicos para professores da Educação Básica no Estado tem ampliado de forma expressiva a presença de alunos graduandos nas salas de aula por meio de contratos precarizados, promovendo, muitas vezes, prejuízos para os estudantes, uma vez que o "professor" graduando ainda não realizou o percurso formativo mínimo necessário para sua atuação profissional e, muitas vezes, não domina os procedimentos que podem o auxiliar no processo da reconstrução didática, mesmo porque, segundo Monteiro (2001, p. 123), “o domínio pelo professor dos conteúdos a ensinar implica ir além do seu conhecimento, tornando necessário o desenvolvimento do que ele chama competência de natureza epistemológica." Nessa perspectiva, entendemos que esse contexto contribui para aprofundar a exploração do trabalhador, ao tempo que expropria da classe trabalhadora condições necessárias à sua formação intelectual.

0 exercício prematuro da docência, sem o caráter de estágio supervisionado, no qual o acompanhamento é realizado sob os cuidados de um professor regente e do professor da área de formação de professores, dificulta o estreitamento do diálogo entre a teoria e a prática. Segundo Caimi (2013, p. 106), os processos de formação docente, fundamentais para a constituição da identidade do professor, precisam:

[...] oportunizar não só a prática em situação real de trabalho como se faz nos estágios supervisionados, mas especialmente garantir estratégias de reflexão, de produção de conhecimentos de natureza pedagógica e de tomada de consciência sobre as condições da docência. A prática, desacompanhada de uma criteriosa observação e análise de si mesma à luz de quadros teóricos e de valores educativos internalizados, possui um efeito formativo bastante limitado. 
Ao analisar a relação entre o tempo de integralização da Graduação em História e o período de início da docência desses docentes, via de regra, percebemos que a grande maioria começa sua trajetória profissional ainda no processo de formação inicial, ou seja, na graduação. Essa relação pode ser visualizada no Gráfico 1 e ajuda-nos a inferir que algumas das estratégias de ensino utilizadas/mantidas por esses docentes na sua prática profissional estão relacionadas aos modelos constituídos e reproduzidos ao início da sua profissionalização.

Gráfico 1 - Graduação e início de carreira

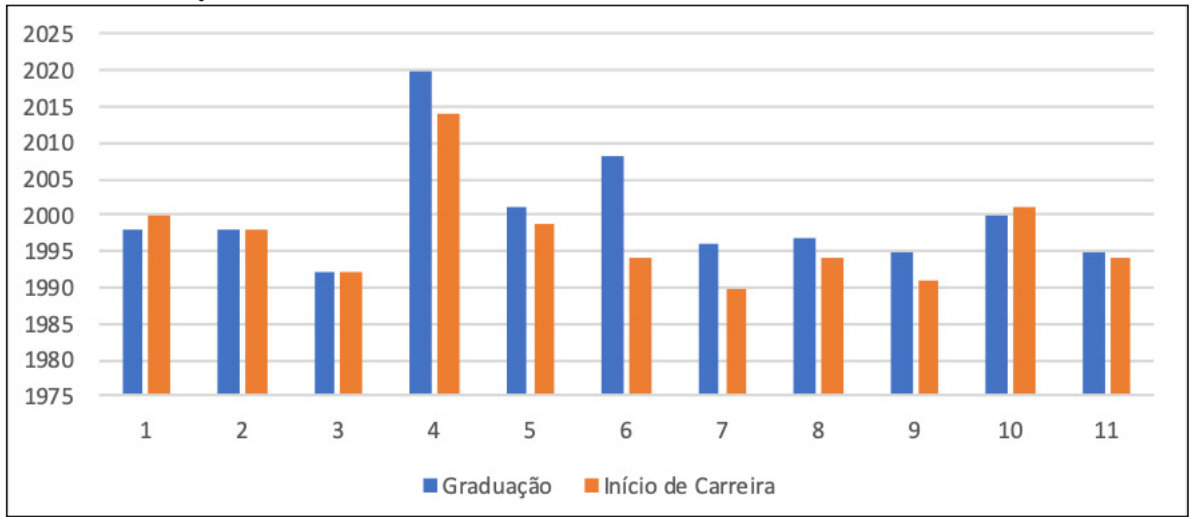

Fonte: os autores.

Agrupamos, no item Formação Continuada dos Docentes, cursos realizados nas seguintes modalidades: stricto sensu, lato sensu e outras formações. Neste ponto, identificamos que apenas dois docentes haviam, à época da aplicação do questionário, integralizado o mestrado. Constatamos, ainda, que a grande maioria dos docentes possui, em média, mais de uma Especialização; destaca-se que neste grupo identificamos também dois mestrandos, um em História Social e um em Educação. As fronteiras entre as áreas de Educação e História são discutidas por Monteiro e Penna (2011), que apontam como elas têm dialogado para compreender a relação epistêmica entre ambas e o fazer pedagógico em sala de aula.

Chamou-nos também a atenção o fato de poucos professores declararem sua participação em cursos de formação continuada de curta duração, embora a oferta de cursos dessa natureza seja uma prática na política do Governo do Estado. Neste grupo identificamos apenas quatro professores, e um destes inclusive relatou que sua participação se devia à necessidade de adquirir o direito à progressão funcional, sem estabelecer qualquer relação com seu aperfeiçoamento profissional; o professor graduando, sujeito desta pesquisa, além 
de não possuir requisitos legais para realizar uma pós-graduação, também não tem se dedicado a participar de cursos de formação continuada de qualquer natureza. 0 Gráfico 2 nos ajuda a visualizar as modalidades da Formação Continuada dos Docentes pesquisados:

Gráfico 2 - Formação continuada

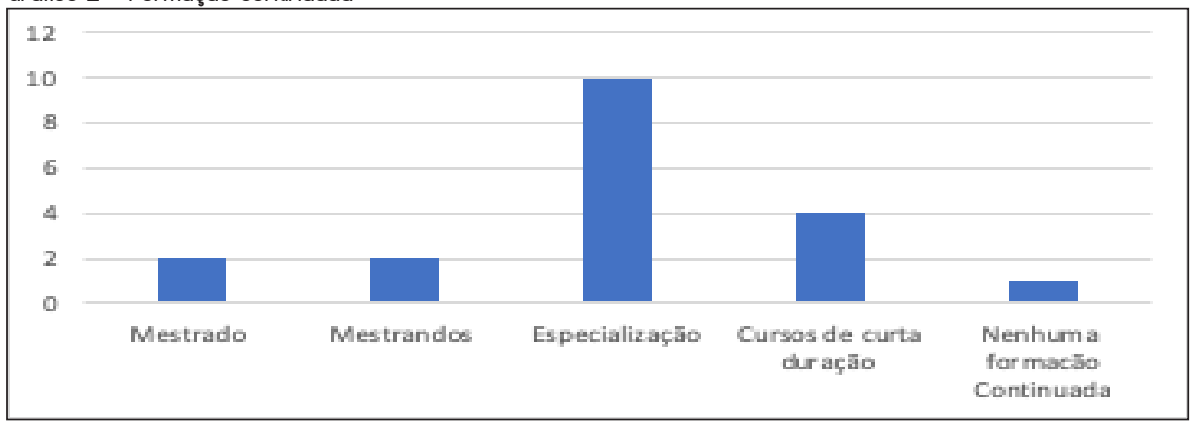

Fonte: os autores.

Os docentes que participaram da pesquisa se graduaram e trabalham nos municípios em que a Universidade Estadual do Sudoeste da Bahia (UESB) e a Universidade do Estado da Bahia (UNEB), possuem campi e oferecem o Curso de Licenciatura em História, que são Vitória da Conquista e Caetité. Embora esses cursos formem turmas de professores há mais de 30 anos, até o momento ainda não conseguiram reunir as condições exigidas pela CAPES para o funcionamento de um Mestrado Acadêmico em História nessas Instituições. Recentemente a UESB teve aprovada pela CAPES sua proposta de oferecimento do Mestrado Profissional de História (ProfHistória), e a expectativa é que na primeira seleção haja um número considerável de professores interessados em ingressar nessa pós-graduação stricto sensu, o que já se observa na procura pelo Mestrado em Educação oferecido por essa Instituição.

Como destacado anteriormente, com exceção do professor graduando, absolutamente todos os outros cursaram ao menos uma pós-graduação latu sensu; a soma de cursos realizados nessa modalidade perfaz o total de 18 , sendo sete em História e $11 \mathrm{em}$ área afins (Ensino, Psicopedagogia, Diversidade). 


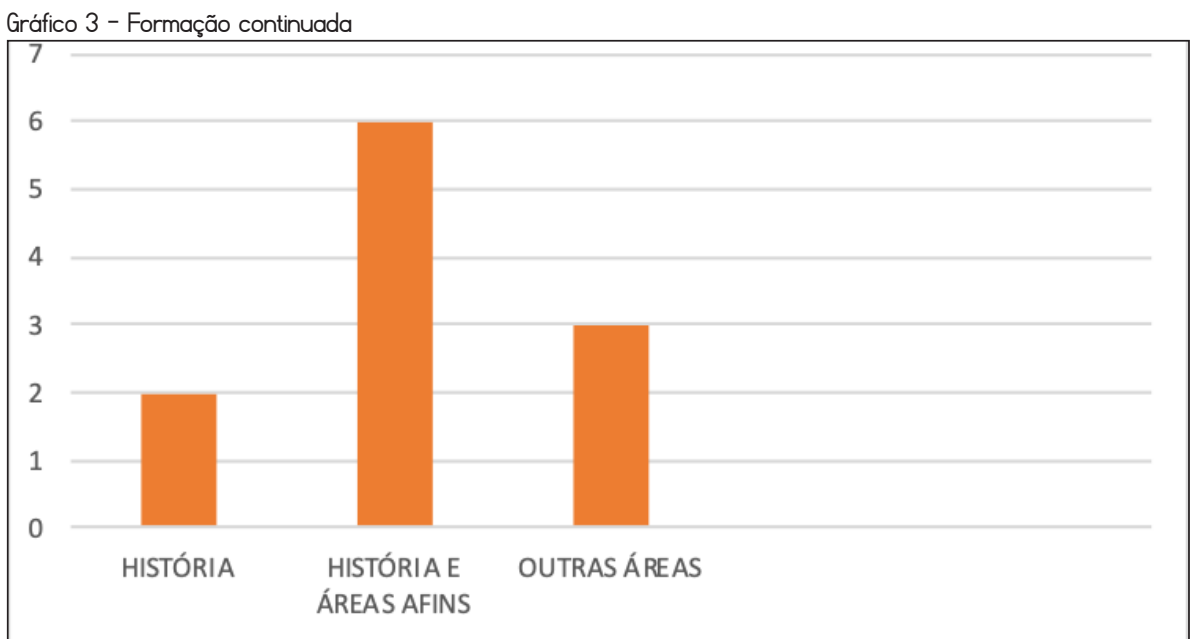

Fonte: os autores.

A formação continuada, na grande maioria das vezes, acontece sem que o docente tenha condições de se afastar integralmente das suas atividades profissionais de sala de aula. Dificuldades do campo pessoal, associadas ao campo profissional, contribuem para que esses profissionais invistam numa formação de pós-graduação lato sensu, inclusive a distância, que demanda menores afastamentos. Motivados por suprir questões apresentadas no seu cotidiano profissional, o docente sente-se impulsionado a construir caminhos alternativos à trajetória então em curso como forma de repensar sua prática.

Feita a análise do campo da formação inicial e continuada, buscamos deslindar o percurso formativo dos 11 docentes a partir das respostas relacionadas ao quantitativo de disciplinas sob sua responsabilidade. Nesse campo identificamos que somente dois professores têm toda sua carga horária com a disciplina de História. Seis têm parte da carga horária registrada com turmas de História, complementando com disciplinas em áreas afins, e três ministram disciplinas de áreas correlatas e em outras áreas (Sociologia, Filosofia, Cidadania e Ética, Identidade, Filosofia e Ética, Educação Física, Direito do Trabalho). No Gráfico 4 é possível visualizar os campos de conhecimento em que os professores têm sua carga horária de regência efetivada em sala de aula. 
Gráfico 4 - Disciplinas em regência

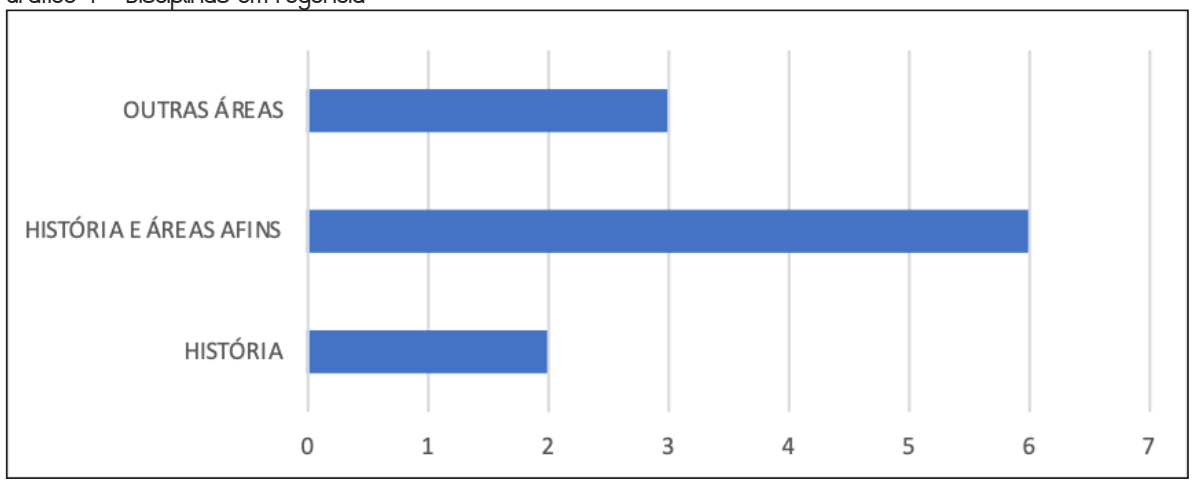

Fonte: os autores.

Dos docentes pesquisados, identificamos que sete trabalham com 40 horas semanais. Ainda desse conjunto, distinguimos dois docentes com regime de trabalho de 60 horas semanais, e dois com vínculo de 20 horas semanais. 0 fato de terem cargas horárias semanais distintas não faz com que haja maiores diferenciações quanto ao quantitativo de alunos sob responsabilidade desses profissionais, fato que pode estar associado à carga horária semanal das disciplinas por eles ministradas nos níveis Fundamental ou Médio, nas modalidades Regular e Educação Profissional, ou na Educação de Jovens e Adultos. 0 Gráfico 5 apresenta uma súmula da distribuição da carga horária e média quantitativa de alunos desses docentes.

Gráfico 5 - Carga horária semanal e número de alunos

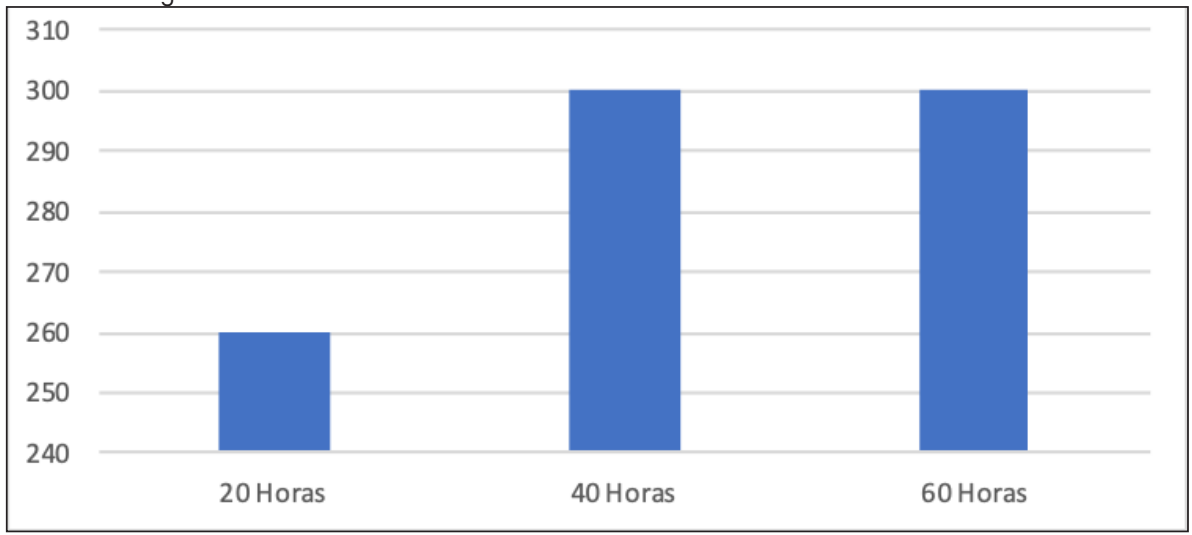

Fonte: os autores. 
De posse das informações relacionadas à carga horária semanal do professor, ao quantitativo de alunos e às disciplinas sob sua responsabilidade, retomamos a discussão acerca das condições de trabalho impostas aos professores da área das Ciências Humanas que, nos últimos anos, vêm sofrendo com a contínua redução de carga horária dos componentes que compõem essa área de conhecimento e, consequentemente, ampliando o número de turmas a serem assumidas. Acreditamos que tais medidas têm impactado na qualidade do trabalho docente que, cada vez mais, conta com menor tempo para repensar e reavaliar sua prática.

Vamos aos dados sobre as escolhas metodológicas e concepções, a fim de visualizarmos parte desses impactos e compreendermos como esses professores ensinam História.

\section{ESCOLHAS METODOLÓGICAS: O QUE DIZEM OS PROFESSORES SOBRE A PRÁTICA DE ENSINO DE HISTÓRIA}

Certamente as estratégias e o estilo de ensinar construídos por professores ao longo de sua carreira revelam muito da sua formação e trajetória, como também as diversas experiências e concepções que os constituem. Na pesquisa realizada, visualizase uma recorrência de práticas que podem indicar uma dada tradição presente na aula de História. Como nos diz Giacomoni (2015, p. 181):

\footnotetext{
Assim agem, de certa forma, todos os professores (de História, ao menos). Atribuímos valores diversos às diferentes temporalidades com que lidamos, conforme nossa formação, crenças, valores, posições políticas, etc. Se as escolhas são presentes, e mesmo inevitáveis, na prática docente, restanos compreender suas motivações e possibilidades, entendendo o próprio professor imerso na historicidade do nosso tempo. (GIACOMONI, 2015, p. 181).
}

Quando questionados sobre quais metodologias consideravam mais adequadas para as aulas de História e solicitados a atribuir valor de concordância, a maioria dos professores apontou como maior concordância o uso da aula expositiva, seguida do trabalho com fontes ou outros documentos e, logo depois, trabalho em grupo. Leitura e discussão de textos dos livros didáticos e trabalho com filmes, documentários ou outros meios de comunicação tiveram grau de concordância mais baixo, embora os participantes não tenham assinalado a opção desacordo com relação a essas metodologias. 
Essa opção da aula expositiva como mais adequada e, provavelmente, mais utilizada pelos professores de História já foi discutida por outros autores, no sentido de identificar a recorrência de uma tradição de aula centrada no professor. Cainelli (2017) aponta essa recorrência que remete ao século XIX.

\begin{abstract}
Em pesquisas recentes sobre o ensino de História no Brasil nos aspectos relacionados a metodologia do trabalho docente podemos afirmar que a forma de ensinar História não se afastou do seu início no século XIX. Muitas das características que predominavam em sala de aula naquele período ainda podem ser vistas no século XXI. Podemos citar entre elas, o ensino mnemônico, as leituras e explicações do texto, o apego ao livro didático, as avaliações de centradas em questões de múltipla escolha. (CAINELLI, 2017, p. 851).
\end{abstract}

Em se tratando da historicidade do sujeito aluno e da forma como o concebemos, Sacristán (2005, p. 17) destaca que, a despeito do aumento e incremento da atenção à criança (incluímos os jovens em situação de escolarização), nosso olhar sobre eles "L...] continua sendo mais magistrocêntrico (visto a partir dos professores), logocêntrico (dependente dos conteúdos mínimos) ou sociocêntrico (olhando as necessidades sociais) do que alunocêntrico (centrado no aluno)."

Essa compreensão do autor estabelece um paralelo com a de Cainelli (2017) quanto à imperativa presença de "práticas canônicas" centralizadoras da transmissão do conhecimento na figura do professor.

Outra questão respondida pelos professores sobre as opções metodológicas dizia respeito aos materiais utilizados nas aulas - além do livro didático -, solicitando a eles também apontar o grau de concordância. Observa-se nas respostas que a maioria colocou em grau crescente de importância o uso de documentos históricos, patrimônio histórico, filmes, música e história em quadrinhos, itens que já estavam disponiveis na questão. No entanto, constava também a opção "outro" que, se assinalada, solicitava apontar o que utilizavam. Nem todos os professores assinalaram essa opção, e os que o fizeram colocaram poesia, jogos, textos impressos, contos literários, entrevistas, coleta de dados, confecção de álbuns, dicionários, portfólios, produção de vídeos, apresentação teatral e relatos da oralidade local.

Essa diversidade de materiais indica que o professor tem variado seu acervo na sala de aula, tem buscado outros materiais didáticos na tentativa de construir uma aula dinâmica e mais interessante para o aluno. Entretanto, cabe-nos indagar se $\circ$ uso desses materiais per si indicaria uma prática diferenciada de ensino ou tem resultado em uma aprendizagem mais significativa. 
Abordando as estratégias utilizadas pelos professores, Giacomini (2015, p. 183) apresenta a seguinte perspectiva:

Percebemos, a partir de Knauss (2005, p. 290), uma grande potencialidade do saber histórico na sala de aula: além do estilo, do formato e das temáticas, os próprios modelos de explicação da História, via de regra mais fechados nas pesquisas historiográficas, são transitados pelos professores, fazendo uso (nem sempre consciente) da diversidade de modelos disponíveis. [...] existe uma interseção entre os conteúdos e modelos historiográficos e o conhecimento curricular, definido por ele como "conteúdo pedagogizado", um lócus de produção e criação centrado na própria ação do professor, que além da historiografia e do currículo congrega as propostas metodológicas habituais da sala de aula laulas expositivas, debates, atividades, apresentações de trabalhos, etc.) e os próprios materiais didáticos (livros didáticos, apostilas, livros paradidáticos, etc.).

Outra questão proposta ao professor diz respeito às estratégias utilizadas nas avaliações em História. A maioria deles assinalou como opção de mais concordância a participação oral em sala, e em segundo lugar duas opções foram assinaladas em grau de concordância: apresentação de trabalhos e atividades realizadas em sala. As outras duas opções disponíveis - prova e atividade do livro didático - receberam grau de concordância em ordem decrescente, a prova maior que o livro didático. Nota-se o livro didático como último nessa sequência, causando certo estranhamento, já que as pesquisas têm mostrado o quanto é recorrente seu uso em sala; no entanto, será que esse uso corresponde em proporção quando se trata de avaliação? No caso dos nossos sujeitos, a resposta é negativa, o livro é a última opção de escolha para se avaliar a aprendizagem histórica. Vale também aqui nos perguntar: em se tratando de avaliação, de que forma o livro didático poderia ser usado? $\mathrm{Na}$ extração de questões, na análise de algum conteúdo? Nas fontes que eles disponibilizam? 0 questionário não possibilitou esse nível de detalhamento das ações avaliativas.

Como a anterior, a questão ainda disponibilizava o item "outros", visando que os professores relacionassem as diversas atividades avaliativas utilizadas. Poucos preencheram essa opção. Entre os que o fizeram, foram apontados: seminários, debate regrado, participação em palestras, oficinas, mesa-redonda, visitas técnicas, visitas em locais da cidade e relatórios. Como a questão solicitava apenas citar, não é possivel visualizar maiores detalhes sobre como essas atividades são realizadas, tampouco os critérios utilizados nos instrumentos e recursos avaliativos. No entanto, listar a participação em atividades como palestras e mesaredonda como recurso avaliativo nos parece vago e pouco significativo para a percepção da aprendizagem histórica dos alunos, fim último da avaliação em História. 
No geral, os dados revelam pouca sistematização e fundamentação teórica dos professores em sua relação com a ciência História, conforme já apontou Cainelli (2017, p. 857) em estudo anterior sobre outra parte desses questionários.

\begin{abstract}
Nesse sentido, uma questão fundamental que se apresenta, qual seja a de se procurar entender quais relações o professor estabelece com as produções da ciência de referência e com as pesquisas sobre ensino de história e novas metodologias para ensinar história e seu trabalho em sala de aula? Que significados a produção do conhecimento pode ter na relação teoria e pratica docente?
\end{abstract}

A aproximação aludida pela autora não sobressai nas respostas dos sujeitos dessa pesquisa. As opções metodológicas e avaliativas indicam uma desconexão com as pesquisas do campo do ensino de História que têm demonstrado alguns caminhos para a construção do pensamento histórico de crianças e adolescentes em sala de aula, como já afirmado pela mesma autora:

\begin{abstract}
Entendemos a partir destes primeiros estudos que predominantemente as aulas de história na educação básica acabam por não considerar as pesquisas recentes que abordam a forma de aprendizagem de crianças e adolescentes. A prática pedagógica do professor de História não considera os aspectos derivados destas investigações em detrimento da tradição consolidada de "cumprir o programa ou vencer os conteúdos do livro didático". (CAINELLI, 2017, p. 856, grifo do autor).
\end{abstract}

Nesse caminho, também destacamos a importância do conhecimento do professor, tanto no campo da teoria da História, quanto no campo pedagógico. Conhecer a ciência de referência não só nos aspectos factuais, mas sua lógica de pensamento, seu método, buscando desenvolver ou aprimorar uma atitude científica, é elemento fundamental para a ação docente. Sobre essa atitude, Gago (2015, p. 30) faz a seguinte advertência:

A ideia que a compreensão da natureza do conhecimento histórico e a sua significância é vital para os professores de História parece ser uma reflexão transversal aos estudos apresentados. Os professores de História no seu quotidiano profissional estão não só a lidar com o conteúdo factual substantivo da História, mas também contribuem para o desenvolvimento do pensamento e consciência histórica dos alunos. Neste sentido, o professor deve potencializar uma atitude reflexiva, científica e antidogmática em relação à realidade. 
Nessa mesma linha, lembram Barca e Gago (2004, p. 396) que "a pesquisa sobre o pensamento histórico de professores tem sugerido que nem todos os adultos historicamente letrados, à partida, demonstram um pensamento histórico actualizado." Ou seja, a dificuldade visualizada em muitos professores em acompanharem a atualização historiográfica e teórica do seu campo de conhecimento tem rebatimento em diversos níveis na sua prática docente.

É necessário ler essa prática também do ponto de vista do professor e seus contextos profissionais e formativos. Nesse sentido, um dos aspectos desse percurso são as concepções que orientam suas escolhas em sala de aula. A forma como percebem a História, como também sua visão de mundo, influencia diretamente na sua prática docente.

\footnotetext{
É a relação que este profissional tem com seu mundo que efetivamente determina a forma de ensinar história, são suas carências de orientação e seus critérios de sentido que dão forma ao conteúdo ensinado ou teoricamente pensado. [...] Entendemos este professor de História como um indivíduo que como qualquer outro participa da história por estar envolvido em seu processo e enquanto tal tem carências de orientação e perspectivas de futuro. (CAINELLI, 2017, p. 855).
}

Baseados nessas preocupações, analisamos as duas últimas questões do terceiro bloco do questionário nas quais foram apresentadas opções que deveriam ser assinaladas conforme o grau de concordância, proposto da seguinte forma: 1 - totalmente de acordo; 2 - de acordo, mas não totalmente; 3 - não concorda nem discorda; 4 - está em desacordo, mas não totalmente; 5 - está totalmente em desacordo. A primeira dessas questões busca a percepção dos professores sobre o conceito de passado, a outra diz respeito ao conceito de história.

Quanto ao conceito de passado, diante das alternativas apresentadas, chamamos atenção para o predomínio de algumas concepções. No caso das afirmativas relacionando passado-presente, como: "o passado é uma necessidade para se conhecer o presente" e "o passado é parte do presente, mas não é igual a ele", praticamente todos os professores assinalaram estar totalmente de acordo. Em nossa opinião, essa forma de os professores compreenderem o passado fomenta uma boa aprendizagem histórica, por concordarmos com Schmidt (2009, p. 15), para quem ela só é efetivamente aprendizagem histórica quando "[...] muda os padrões de interpretação do passado, o que pressupõe um processo de internalização dialógica e não passiva do conhecimento histórico, além de uma exteriorização para fora, no sentido de mudar a relação com a vida prática e com o outro."

Destacamos que a compreensão dos professores quanto ao estabelecimento de relações temporais passado e presente é importante para aproximar o aluno da história e das carências de orientação do nosso tempo. Nesse sentido, Gago (2007, p. 128) recomenda 
que na aula de história seja enfatizado "[...] o que existia no Passado e já não se possui, bem como propor exercícios de comparação entre realidades passadas mais próximas da que se tenta compreender ou mesmo realidades contemporâneas e entre si diversas."

Em se tratando de outras opções da questão, o mesmo grau de concordância pode ser observado com relação à ideia de que o passado é reconstruído e representado mediante interpretação e que ele não é algo linear e fixo. Cruzando esse último aspecto com os modos de ensinar anunciados pelos professores, dentre os quais predomina 0 modelo tradicional de ensino - conforme anunciado anteriormente -, como explicar essa visão refinada sobre o passado e, paralelamente, a manutenção dessas práticas ao abordar o conteúdo histórico com os alunos?

No que diz respeito à capacidade do historiador de se distanciar do passado e seu ofício de reconstruir os fatos, houve uma variação elevada no grau de concordância/ discordância, dificultando caracterizar qual concepção predomina entre os professores pesquisados. 0 mesmo ocorreu quanto à afirmativa “0 passado só pode atingir a plausibilidade, nunca a objetividade", para a qual não houve uma assinalação predominante.

Fazendo um processo de autocrítica, avaliamos que qualquer instrumento é passivel de falhas, tanto nas questões propostas quanto nas respostas dos sujeitos. Em nosso caso, a dificuldade em identificar o predomínio de algumas concepções dos professores pode estar relacionada à forma como as questões foram apresentadas, ou mesmo ao seu conteúdo, como também à falta de compreensão, por parte dos sujeitos, sobre o que propõem as questões, riscos apontados por Barca (2000, p. 115).

Ainda sobre a importância de relacionar passado e presente para a compreensão e um olhar mais refinado sobre o presente no processo de educação histórica, Rüsen (2006, p. 9) defende que "alcançar o conhecimento empírico do passado poderia levar a um insight sobre o movimento das forças do presente", dotando a história de sentido para alunos e professores.

No tocante ao conceito de História, chamam atenção dois itens marcados pelos professores. No primeiro deles - "A História é uma ciência que investiga o passado da humanidade e o seu processo de evolução, tendo como referência um lugar, uma época, um povo ou um individuo específico" -, apenas uma professora assinalou discordância, a grande maioria concordou plenamente. Quanto ao segundo - "A História é mestra da vida" -, houve uma discordância plena, duas discordâncias parciais e o restante concordou. Ou seja, a visão de História desses professores ainda é marcada pela ideia de passado, evolução com uma função exemplar.

A ideia de História como relato do passado que ensina ao presente, atravessada pela concepção de evolução, há muito já foi problematizada, ressaltando os desdobramentos 
dessa visão no desprovimento de ferramentas para nos situar no tempo e perceber o percurso humano marcado por mudanças.

A História como conhecimento tem suas especificidades, como fala Borries (2016, 2016, p. 171, grifo do autor):

[..] história é um modo distinto de pensamento, um acesso metódico para um melhor entendimento do mundo e de si, uma ferramenta para decodificar fenômenos e orientações no presente e no futuro - basicamente efetuada por narrativas "verdadeiras" sobre eventos passados, mudanças e desenvolvimentos.

Por que é importante problematizar a visão de História dos professores? Certamente, como falado anteriormente, a prática de ensino de qualquer professor é marcada por suas concepções, pela maneira como vê o mundo. 0 campo do ensino de História tem defendido a perspectiva de que o objetivo de ensinar e aprender História é possibilitar/ proporcionar a formação do pensamento histórico, ou seja, ajudar crianças e jovens a se situarem no tempo e se sentirem sujeitos históricos, não apenas acumularem informações sobre fatos históricos.

[...] o problema do "ensino de História", na época da (pelo menos a quarta fase) globalização e (pelo menos a segunda) era pós-Nacional, não é um cânone de dados para conservar e transmitir para a próxima geração da sociedade e suas subculturas ("população" em vez de uma "nação" mítica como uma comunidade "inventada/imaginada"), mas uma maneira de construir competências de pensar historicamente diferentes contextos (como raça, língua, idade, sexo, religião, cultura, região, classe, poder, riqueza, profissão, consumo, estilo de vida, mentalidade). (BORRIES, 2016, p. 175, grifo do autor).

Nessa perspectiva, a compreensão de como o professor pensa a História e seu campo epistemológico é de fundamental importância, como nos alerta Barca (2011 apud CAINELLI, 2017, p. 855),

\footnotetext{
[...] entender como se formam as ideias históricas, em primeiro lugar porque só se pode mudar aquilo que se conhece e em segundo lugar para promover um conteúdo histórico estruturante que não valorize apenas a reprodução pouco refletida de conhecimento de temáticas curriculares, mas também a formação da consciência Histórica. As ideias serão coletadas através da construção de narrativas pelos professores, entendendo a narrativa no sentido atribuido por Isabel Barca (2011) "como expressão de ideias sob
} 
qualquer formato - que se comunica a compreensão histórica e os sentidos que thes são atribuidos".

Outro bloco de questões do instrumento solicitava aos professores a construção de narrativas sobre como ensinariam determinados conteúdos substantivos da História. Neste artigo não priorizamos esses dados, no entanto trazemos aqui algumas reflexões. No geral percebemos uma tendência do professor em explicar primeiro o conteúdo, inclusive sob a perspectiva de conceitos, para depois propor alguma atividade na qual o protagonista seja o aluno.

Uma das questões perguntava: "Como você explicaria o processo do descobrimento do Brasil para uma turma de alunos do $8^{\circ}$ ou $9^{\circ}$ ano? Elabore uma narrativa.". As respostas caminham no sentido de problematizar o conceito de descobrimento e narrar sobre as grandes navegações. Alguns professores destacam a situação do Brasil antes da chegada dos europeus. No entanto, quase todos apontam a aula como explicação do professor. Por exemplo, o professor LSS diz:

\footnotetext{
Mostraria que o descobrimento do Brasil fez parte do processo histórico do século XIV de fortalecimento e consolidação do capitalismo e que estava ligado ao fenômeno das grandes navegações. Para isso, é necessário conceituar o sistema capitalista e retomar ao seu surgimento. Mostrando que as grandes navegações foram parte desse processo, assim como a chegada dos portugueses ao Brasil. (informação verbal, grifo nosso).
}

Percebe-se nessa fala uma preocupação com os aspectos conceituais e em situar o fato num contexto mais amplo. No entanto, não há manifestação de preocupação em envolver o aluno na problematização e no exercício de pensar historicamente. 0 verbo mostrar indica uma ação do professor no sentido de levar o conhecimento pronto ao aluno. Outro aspecto observado é a preocupação com as origens, tão cara aos profissionais de História e constante preocupação de professores, que expressam a necessidade de sempre retornar ao surgimento como requisito para a compreensão dos alunos, mais uma vez desconsiderando os estudos no campo do ensino de História que já demonstram outros caminhos para se aprender História.

Cabe agora relacionar esses dados relativos às práticas de ensino com a formação, o que faremos a seguir. 


\section{RELAÇÃO FORMAÇÃO X PRÁTICA DE ENSINO: O QUE APONTAM OS DADOS}

Analisados os dados, resta-nos identificar e problematizar até que ponto há diferenças nas escolhas metodológica a depender do perfil formativo, ou seja, se a formação continuada impacta, no sentido de munir o professor para uma prática docente mais significativa no processo de educação histórica.

Acreditamos que os saberes das ciências de referência e os saberes pedagógicos - adquiridos tanto na formação inicial quanto continuada - ampliam o repertório do professor e reverberam em sua prática, tal qual assinala Cainelli (2017, p. 857): “A pluralidade de saberes necessários à formação docente leva-nos a ponderar a importância dos saberes relativos à ciência de referência para a formação do docente e a pluralidade dos conhecimentos que atuam na ação pedagógica."

No entanto, nossa compreensão é de que se esse conhecimento não se traduzir em concepções claras para os professores acerca, por exemplo, de quais saberes o aluno porta antes e além da escola, como aprende, quais são suas ideias históricas e quais sentidos atribui ao conhecimento histórico, buscando, com isso, aprimorar suas práticas e, por meio delas, contribuir para o desenvolvimento do pensando histórico dos alunos e para a ampliação de seu quadro conceitual, pouco concretizará um ensino que atenda a essas perspectivas. Sobre esse aspecto, Gago (2015, p. 27), assinala que

\footnotetext{
A educação histórica partilhando as ideias do construtivismo social aponta ser crucial abordar o ato educativo atendendo às ideias, ao quadro conceptual do aprendente de modo a que este momento de transformação seja um processo de procura contínua de sofisticação na construção do pensamento pelo aprendente/ formando. Estas premissas deverão ser partilhadas por todos os educadores nos diversos graus de ensino: do ensino básico ao ensino superior. Urge compreender se estes quadros conceptuais de futuros professores e de professores de História são claros para os próprios professores e que reflexos podem ter na sua prática.
}

Cruzando os dados do perfil dos professores com os referentes às escolhas metodológicas, não visualizamos diferenças marcantes que indiquem aprimoramento proporcionado por maior tempo e grau de formação. Não temos como afirmar categoricamente o que explicaria esse fenômeno, mas podemos sugerir algumas possibilidades: tempo de experiência na docência, tipo de formação e especialização em outras áreas (direito, gestão), diferentes do campo do ensino de História que, segundo nossa compreensão, propiciaria maior expertise. 
Ao analisar as narrativas construidas pelos professores acerca de como explicariam determinados temas da História do Brasil para alunos do ensino fundamental II, identificamos alguns traços predominantes.

Um ponto de destaque é o descompasso entre os avanços historiográficos sobre os temas - Imigração e Descobrimento do Brasil - e as explicações por eles indicadas. Um exemplo é a recorrência do debate sobre intencionalidade versus acaso relacionada à descoberta do Brasil, discussão já superada no campo historiográfico.

Outra característica igualmente marcante na maioria das narrativas é o conhecimento centrado no professor, atitude magistrocêntrica, segundo a acepção de Sacristán, portadora de poucas estratégias que consideram o aluno como sujeito da aprendizagem.

Ao narrar fatos históricos, muitos professores recorrem à explicação das origens, voltando no tempo para identificar possíveis causas. Essa lógica indica uma tradição ainda presente nas aulas de História de explicar com base na relação causa e efeito.

Por outro lado, observamos a indicação, nessas narrativas, da utilização de fontes históricas variadas na abordagem dos temas, o que pode indicar uma atualização metodológica, aproximando a história escolar da epistemologia da História, ou seja, levando para o ensino de história o exercício metodológico de uso de fontes para construção do conhecimento histórico. Essa prática pode ser provocada pela própria formação inicial, ou mesmo pela atualização que o livro didático vem proporcionando nos últimos anos.

No entanto, a indicação de fontes não vem associada a um aprofundamento teórico, a maioria das narrativas demonstra uma discussão conceitual superficial, sem apresentar aspectos do debate historiográfico. Duas professoras apenas indicam maior complexidade e domínio mais consistente nesse aspecto, uma com mestrado e outra com mestrado em curso na área de educação à época da pesquisa.

Outra marca observada na maioria das narrativas dos professores é a concentração da fala no passado, poucos estabelecem intercâmbios com o tempo presente. Perspectiva preocupante, quando já é consenso a necessidade de estabelecer relações temporais entre presente, passado e futuro, objetivando construir sentido para a vida prática, ou seja, aprender História para melhor compreender as relações humanas no tempo presente.

Duas professoras com especialização declararam cursarem mestrado, e outra tem mestrado concluido. Destas, duas se destacam no sentido de pensarem o processo de ensino e aprendizagem da História de forma mais aprofundada e com preocupação de tratar o aluno como sujeito da aprendizagem. Suas narrativas possuem maior grau de coerência e domínio teórico-metodológico da História. 
Rüsen (2010) afirma ser a narrativa histórica quem dá à consciência histórica a possibilidade de construção de sentido sobre a experiência do tempo. Ela explicita essa consciência em um todo coerente, já que tem a capacidade de construir sentido histórico, explicar. Assim, esse autor defende que

[..] somente quando a história deixar ser aprendida como a mera absorção de um bloco de conhecimentos positivos, e surgir diretamente da elaboração de respostas a perguntas que se façam ao acervo de conhecimentos acumulados, é que poderá ser ela apropriada produtivamente pelo aprendizado e se tornar fator de determinação cultural da vida prática humana. (RÜSEN, 2010, p. 44).

Na questão sobre como explicaria a imigração para alunos do $9^{\circ}$ ano e sua relação com a história local, duas delas deram conta de pensar com complexidade e ainda descrever como desenvolveriam em sala uma sequência de atividades, apontando uso de fontes, provocando reflexão multiperspectivada e relacionada ao presente. Por exemplo, a professora MAM fez uma longa narrativa sobre a temática e apresentou possibilidades de trabalho em sala. Para esclarecer, seguem alguns trechos da sua fala:

Os processos migratórios são fenômenos que ocorrem há muito tempo. Existem vários exemplos que poderíamos lembrar de povos que imigraram por motivos religiosos, econômicos, ambientais, sociais e políticos lexplorar esses exemplos com os alunos, discutir e apresentar o conceito de imigração).

[...] Divisão da turma em equipes para pesquisar e apresentar esses casos específicos.

É necessário mapear as regiões do Brasil que receberam esses imigrantes. [...] Após apresentar o mapa dos deslocamentos desses imigrantes pelo território brasileiro, explorá-lo com as seguintes questões: A nossa região recebeu imigrantes? Na nossa cidade também ocorreu processos migratórios? Podemos identificar aqui uma comunidade formada por povos vindos de outro lugar? Existem características culturais marcantes de outros povos? Como se formou a cidade? Os tropeiros que passavam por aqui em direção ao interior podem ser considerados imigrantes? Quais os vestígios de imigração na nossa região larquitetura, festas, aspectos culturais, comidas, características físicas)?

Mais recentemente, observamos um processo migratório na América Latina. Bolivianos, peruanos, venezuelanos cruzam nossas fronteiras. 0 que teria causado essa nova onda migratória? Por que a escolha do Brasil? Existem políticas públicas para acolher os imigrantes? Qual a receptividade dos brasileiros em relação a eles? [...] (informação verbal).

Um aspecto também percebido na citação apresentada é a relação estabelecida pela professora entre aspectos gerais e particulares da História, ou seja, pensa o micro e o 
macro em movimento. Nas demais narrativas isso pouco aparece, inclusive vários professores nem incluíram a relação com o local, embora fosse solicitado que o fizessem.

\section{ALGUMAS CONSIDERAÇÕES}

Os dados pesquisados não são suficientes para compreendermos as possibilidades e os limites da prática docente dos professores de História. Aqui ensaiamos algumas reflexões, o que fortalece a necessidade, já há muito identificada, de ouvir os professores e investigar mais de perto a sala de aula. Como ensinam História? 0 que pensam sobre sua prática? Em quais contextos atuam? Quais sentidos e funções atribuem ao ensino e aprendizagem da História? Quais ideias históricas têm sobre determinados temas? Refletem sistematicamente sobre sua prática?

Quando pensamos na formação, particularmente no Estado da Bahia, os questionários indicam que, muitas vezes, é fruto de ações individuais dos professores que buscam se qualificar, tendo como parâmetro seus interesses pessoais, notadamente aqueles relacionados à melhoria salarial, ou mesmo às oportunidades que aparecem. Quando a formação resulta da ação da Secretaria de Educação, geralmente são temáticas ligadas aos saberes pedagógicos, sem uma relação mais aprofundada com a ciência de referência dos professores, por isso muitos informaram terem cursado especialização em gestão pedagógica. Diante desse contexto, indagamo-nos: quais oportunidades institucionais e sequenciadas têm esses professores no sentido de aprofundamento com seu campo de atuação?

Os objetivos do conhecimento histórico escolar e da ciência História são diferentes, mas podemos pensar em sentidos semelhantes quando refletimos sobre o papel da História e sua função social. Lembrando Albuquerque Júnior (2012), a História nos faz humanos e nos proporciona uma orientação temporal e um olhar mais tolerante para o diferente, logo, seja na escola seja em outros espaços, o conhecimento histórico é imprescindível.

Como esse conhecimento possibilita a construção/reelaboração de sentidos na sala de aula? 0 s professores percebem e trabalham perseguindo essa perspectiva? 0 s dados trabalhados até aqui não dão conta de responder tais questões. No entanto, provocam-nos a entender mais de perto as escolhas e os caminhos traçados por professores de História em contextos diversos. 


\section{REFERÊNCIAS}

ALBUQUERQUE JÚNIOR, D. M. de. Fazer defeitos nas memórias: para que serve o ensino e a escrita da história? In: GONÇALVES, M. de A. et al. (org.). Qual o valor da história hoje? Rio de Janeiro: Editora FGV, 2012. p. 21-39.

BARCA, l.; GAGO, M. Usos da narrativa em história. In: MELO, M. do C. de; LOPES, J. M. (org.). Narrativas históricas e ficcionais: recepção e produção para professores e alunos. In: ENCONTRO SOBRE NARRATIVAS HISTÓRICAS E FICCIONAIS, 1., 2004, Braga. Actas [...] Braga: Centro de Investigação em Educação do Instituto de Educação e Psicologia da Universidade do Minho, 2004. p. 29-40.

BARCA, I. 0 papel da educação histórica no desenvolvimento social. In: CAINELLI, M.; SCHMDT, M. A. (org.). Ensino de história: teoria e pesquisa. ljuí: Ed. Unijuí, 2011.

BARCA, I. 0 pensamento histórico dos jovens. Ideias dos adolescentes acerca da provisoriedade da explicação histórica. Braga: Centro de Estudos em Educação e Psicologia, Instituto de Educação e Psicologia da Universidade do Minho, 2000.

BORRIES, B. von. Competência do pensamento histórico, domínio de um panorama histórico ou conhecimento do cânone histórico. Educar em Revista, Curitiba, n. 60, p. 171-196, abr./jun. 2016.

CAIM, F. Professores iniciantes ensinando história: dilemas de aula e desafios da formação. Revista História Hoje, Rio de Janeiro, v. 2, n. 3, p. 87-107, 2013.

CAINELLI, M. R. Investigando as práticas de ensino de professores de história na educação básica (Brasil - 1998 - 2016). Epistemologias e ensino da história. In: CONGRESSO DAS JORNADAS INTERNACIONAIS DE EDUCAÇÃO HISTÓRICA, 16., 2017, Porto. Actas [...] Porto: Centro de Investigação Transdisciplinar “Cultura, Espaço e Memória”, 2017. p. 848-865.

GAGO, M. Concepções de passado como expressão de consciência histórica. Currículo sem Fronteiras, v. 7 , n. 1, p. 127-136, jan./jun. 2007.

GAGO, M. Consciência e narrativa histórica: desafios educativos aos professores. Revista Acadêmica Licencia \& Acturas, Ivoti, v. 3, n. 2, p. 26-35, jul./dez. 2015.

GIACOMONI, M. P. 0 professor que cativa: entre a narrativa de História e o cuidado de si. OPSIS, Catalão, v. 15, n. 1, p. 179-196, 2015.

LIBÂNEO, J. C. A organização e a gestão da escola: teoria e prática. 5. ed. Goiânia: Editora Alternativa, 2004.

MONTEIRO, A. M. F. da C.; PENNA, F. de A. Ensino de história: saberes em lugar de fronteira. Educação \& Realidade, Porto Alegre, v. 36, n. 1, p. 191-211, jan./abr. 2011. 
MONTEIRO, A. M. F. da C. Professores: entre saberes e práticas. Educação \& Sociedade, Campinas, ano XXIl, n. 74, abr. 2001.

NÓVOA, A. Os professores e sua formação. Lisboa: Dom Quixote, 1992.

PIMENTA, S. G. (org.). Saberes pedagógicos a atividade docente. São Paulo: Cortez, 1999.

RÜSEN, J. Aprendizado histórico. In: SCHMIDT, M. A.; BARCA, l.; MARTINS, E. de R. (org.). Jörn Rüsen e o ensino de história. Curitiba: Editora da UFPR, 2010. p. 41-49.

RÜSEN, J. Didática da história: passado, presente e perspectivas a partir do caso alemão. Práxis Educativa, Ponta Grossa, v. 1, n. 2, p. 7-16, jul./dez. 2006.

SACRISTÁN, J. G. 0 adulto constrói o menor e o aluno. In: SACRISTÁN, J. G. 0 aluno como invenção. Tradução: Daisy Vaz de Moraes. Porto Alegre: Artmed, 2005. p. 11-24.

SCHMIDT, M. A. A formação do professor de história e o cotidiano da sala de aula: entre o embate, o dilaceramento, e o fazer histórico. In: ENCONTRO PERSPECTIVAS DO ENSINO DE HISTÓRIA, 2., 1996, São Paulo. Anais [...] São Paulo: USP, 1996. p. 115-128.

SCHMDT, M. A. Literacia histórica: um desafio para a educação histórica no século XXI. História e Ensino, Londrina, v. 15, p. 9-22, ago. 2009.

Endereço para correspondência: Estrada Bem Querer, Km-04 3293, 3391 Campus de Candeias, Bahia, Brasil; mcristina.pina@gmail.com

Roteiro, Joaçaba, U. 45, p. 1-24, jan./dez. 2020 | e23054 |E-ISSN 2177-6059 
